\title{
Spinal cord compression following vertebral osteomyelitis due to Alkalescens-Dispar
}

\author{
J. BRIGGS AND R. G. LASCELLES \\ From the Departments of Clinical Pathology and Neurology, St. Thomas's Hospital, London
}

SYNOPSIS A case of osteomyelitis of the spine is described. A member of the Alkalescens-Dispar group was isolated from the lesion.

In Great Britain osteomyelitis is most commonly caused by Staphylococcus aureus. Less frequently the responsible organism may be the tubercle bacillus or one of the members of the Salmonella group. The following case illustrates an osteomyelitic process occurring in the presence of an organism of the group Alkalescens-Dispar. No previously recorded instance of this type of infection can be found in the literature.

\section{CASE HISTORY}

A 78-year-old Lambeth woman was admitted to the Neurological Unit of St. Thomas's Hospital on 9 October 1961 under the care of Dr. J. St. C. Elkington. She had been in good health until June when she began to experience abdominal discomfort, nausea and vomiting, and felt lethargic and weak. She was admitted to another hospital on 21 July where she was found to have chronic pyelonephritis due to Proteus vulgaris in association with mild diabetes mellitus. The latter was treated by dietary measures alone and the urinary infection with sulphatriad and mist. pot. cit. Her symptoms rapidly subsided, her urine became sterile, and she was discharged from hospital on 5 August.

In mid-August she slipped and fell heavily on her back. Afterwards she developed an aching pain in the lumbar region of the spine and as this persisted she was readmitted to hospital. A radiograph of the lumbar spine was taken and showed degenerative changes only. The pain settled under observation and she was discharged on 18 September. Over the next few days the pain returned and gradually increased in severity; it did not radiate but was markedly worsened by coughing and straining. Her legs became weak and by early October she had become bed-ridden. She had experienced no difficulty with micturition and her bowels were normal.

On examination, the patient was an obese rather garrulous old lady. Temperature and pulse were normal and she showed no evidence of intellectual impairment. The fundi, cranial nerves, and upper limbs were normal.
The lower limbs were hypotonic and their power was markedly reduced. Both quadriceps were wasted. Sensory appreciation of touch, pin-prick, and temperature were normal, but vibration sense was absent at both ankles. The deep reflexes in the upper limbs were equal and normal, abdominal reflexes were absent, knee and ankle jerks diminished, and her plantar responses extensor. General examination was normal and her blood pressure was $140 / 90 \mathrm{~mm}$. Hg.

A blood count showed a haemoglobin of $82 \%$ with a white cell count of 9,600 per c.mm. (neutrophils $89 \%$, lymphocytes $9 \%$, monocytes $2 \%$ ). The erythrocyte sedimentation rate (Westergren) was $51 \mathrm{~mm}$. in the first hour. The blood Wassermann reaction and Reiter's protein complement-fixation test were negative, and the plasma electrolytes normal. The Widal test was negative and urine culture sterile. A radiograph of the chest was normal but the spine showed degenerative changes in the lumbar region and marked destruction of the eleventh and twelfth thoracic vertebrae (Fig. 1).

Lumbar puncture was carried out on 10 October. Considerable difficulty was experienced in the procedure owing to lack of cooperation from the patient and the pressure was not recorded. A slightly blood-stained fluid was obtained which contained 5,000 red blood cells per c.mm., 10 white blood cells per c.mm., and $200 \mathrm{mg}$. protein. The Wassermann reaction, Reiter's protein complement-fixation test, and the Lange curve were normal.

The diagnosis at this stage appeared to rest between an infective and a neoplastic process at the level of the eleventh and twelfth thoracic vertebrae, causing spinal cord compression.

On 19 October a vertebral biopsy was carried out by Mr. Furlong and specimens were sent for histology and culture. The histological specimens were fragments of bone and fibrous tissue showing acute and chronic inflammatory cell infiltration but no evidence of malignancy or tuberculosis (Fig. 2).

The cultures yielded a heavy growth of each of two Gram-negative bacilli. Both organisms were inoculated into sugars. After overnight incubation, one gave reactions suggestive of Alkalescens-Dispar, i.e., acid in glucose and mannite, a positive indole production, and 


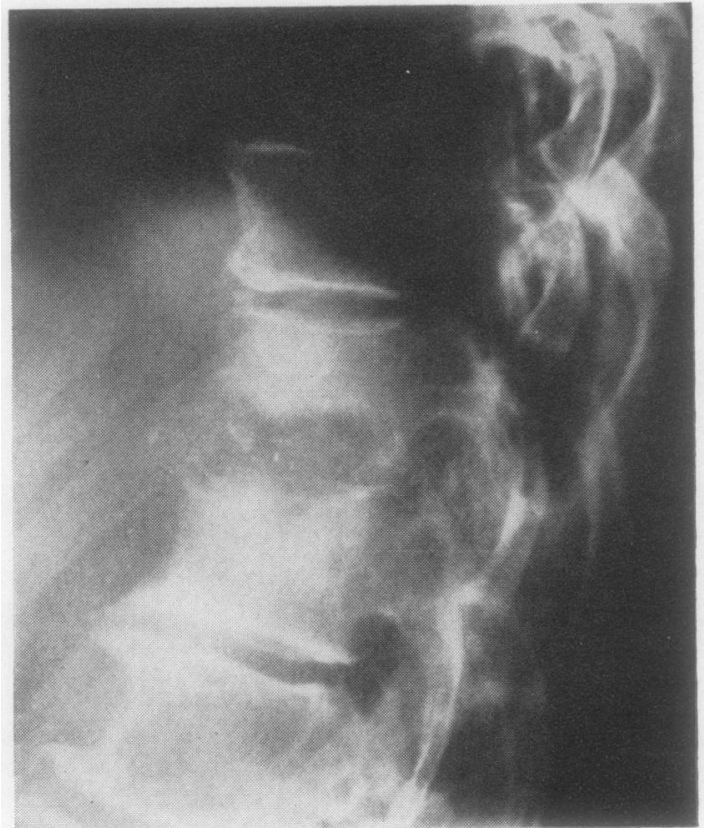

FIG. 1. Radiograph showing degererative changes in the lumbar region. negative motility test. Serological investigations on the organism supported this opinion. The identity was con-은 firmed by Dr. Carpenter at the Dysentery Reference Laboratory, who found it to be Alkalescens-Dispar $\mathrm{O}_{\rightarrow}$ type 1 , behaving typically biochemically and serologically으 The second organism failed to ferment any of the sugarso tested and grew in the form of a thick pellicle in these $\overline{\bar{c}}$. media. This organism was also sent to the Dysenteryd Reference Laboratory; it has defied precise identification but may possibly be a Flavobacterium (King, 1959).

The patient was treated with chloramphenicol and tetracycline (both $250 \mathrm{mg}$. q.d.s.). No attempt was made-to culture the blood as the antibiotic treatment was $\vec{w}$ instituted immediately the organisms were isolated from? the vertebral biopsy. Neither organism was ever grown? from the urine. Stool culture was also negative. During the course of the illness, antibodies were never found in the patient's serum against her own strain of Alkalescens Dispar, using a boiled or unboiled broth culture, as recommended by Frantzen $(1950,1951)$.

Following a period of extreme confusion and dis $\stackrel{\circ}{2}$ orientation the patient began to recover. On 7 February 1962, when she was able to move both her feet and raisक her legs off the bed, she was transferred to a country hospital for convalescence.

\section{DISCUSSION}

Kauffmann in 1949 proposed a classification of the

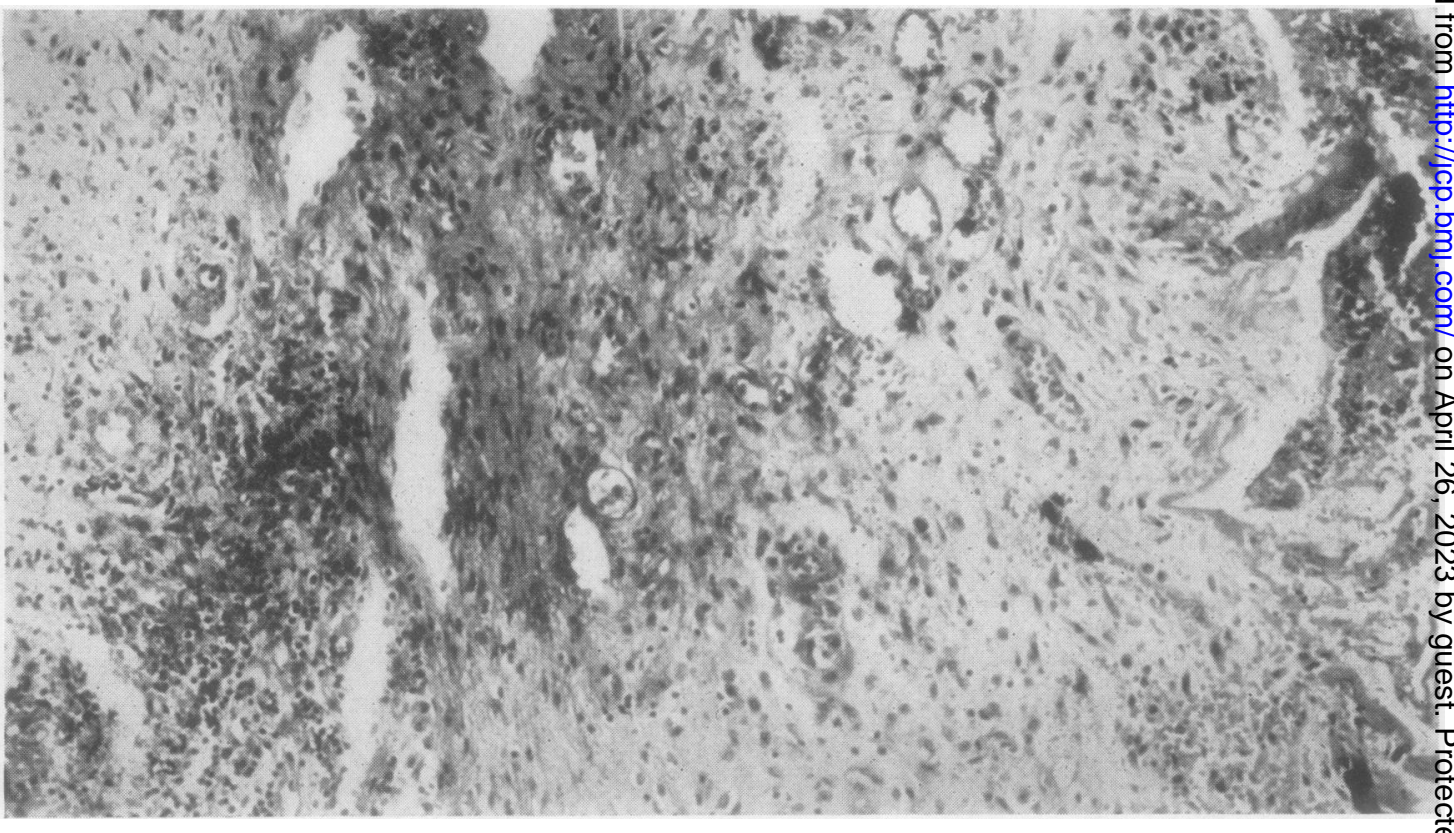

FIG. 2. Section from vertebral biopsy showing fragments of bone and fibrous tissue in which there was acute and chroniç inflammatory cell infiltration but no evidence of malignancy or tuberculosis. 
family Enterobacteriaceae in which the microorganisms known as Shigella alkalescens and Shigella dispar were removed from the genus Shigella and included in a special group termed the Alkalescens-Dispar group. This new group was placed with the Eschericheae.

This reclassification has subsequently been supported, notably by Frantzen $(1950,1951)$, and by Ewing, Taylor, and Hucks (1950). The organisms now contained in this group have been considered to be of doubtful pathogenicity, although $S h$. alkalescens was described by Smith and Fraser (1928) as the cause of a continuous fever. It has also been isolated from blood cultures by Starkey (1934) and from cases of bacilluria by Snyder and Hanner (1937). Benjafield and Halley (1938) have incriminated the organism as the cause of infective mono-articular arthritis, but in this instance the bacteria were only isolated from the bowel. $S h$. dispar occurs in the stools of healthy individuals. Breed, Murray, and Smith (1957) state that it is also to be found in the stools of patients suffering from dysentery and in the urine of persons having cystitis, pyelitis, or pyelonephritis. At this hospital there have been four cases of urinary tract infection associated with organisms of the Alkalescens-Dispar group during the past two years.

The present case illustrates an osteomyelitic process occurring in association with AlkalescensDispar. The work of MacKenzie and Ratner (1934) shows that cases of pyelonephritis due to $B$. alkalescens may have positive blood cultures. Although none of their cases showed evidence of osteomyelitis it is reasonable to assume that when this complication occurs urinary infection could well be the starting point. In the present case urinary tract infection was present but $P r$. vulgaris was the only organism isolated. In spite of this it is possible that Alkalescens-Dispar was responsible for the initial infection. The absence of demonstrable antibodies in the patient's serum, in contrast to the findings of Cassel and O'Loughlin (1950), provides no assistance in the solution of this problem.

Our grateful thanks are due to Dr. J. St. C. Elkington and Dr. J. L. Pinniger for their help and encouragement in the preparation of this paper.

\section{REFERENCES}

Benjafield, J. D., and Halley, G. S. (1938). Lancet, 2, 616.

Breed, R. S., Murray, E. G. D., and Smith, N. R. (1957). Bergey's Manual of Determinative Bacteriology, 7th ed., p. 390. Williams and Wilkins, Baltimore.

Cassel, W. A., and O'Loughlin, J. (1950). Amer. J. clin. Path., 20, 287. Ewing, W. H., Taylor, M. W., and Hucks, M. C. (1950). U.S. Public Health Reports, 65, 1474.

Frantzen, E. (1950). Acta path. microbiol. scand., 27, 236. - (1951). Ibid., 28, 103.

Kauffmann, F. (1949). Ibid., 26, 879.

King, Elizabeth O. (1959). Amer. J. clit. Path., 31, 241.

MacKenzie, D. W., and Ratner, M. (1934). J. Urol., 31, 671.

Smith, J., and Fraser, A. M. (1928). J. Path. Bact., 31, 511.

Snyder, M. L., and Hanner, J. P. (1937). J. infect. Dis., 60, 61.

Starkey, D. H. (1934). J. Canad. med. Ass., 31, 42. 